\title{
OPTIMAL TEMPERATURE CONTROL IN A BATCH POLYMERIZATION REACTOR USING DEADBEAT CONTROL
}

\author{
Sevil ÇETINKAYA GÜRER ${ }^{1}$, Duygu ANAKLI ${ }^{1,}$ *, Hale HAPOĞLU ${ }^{2}$ \\ ${ }^{1}$ Department of Chemical Engineering, Faculty of Engineering, Sivas Cumhuriyet University, Sivas, Turkey \\ ${ }^{2}$ Department of Chemical Engineering, Faculty of Engineering, Ankara University, Ankara, Turkey
}

\begin{abstract}
In this study, Deadbeat control of a jacketed batch reactor in which styrene polymerization occurs under isothermal conditions has been investigated experimentally and by simulation to achieve a specific constant number average chain length and conversion in a minimum time. It was founded that Deadbeat control provided a good performance in maintaining the reactor temperature at its set point at the isothermal conditions. It is obtained that desired final conversion and number average chain length values were almost achieved.
\end{abstract}

Keywords: Polymerization reactor, Deadbeat control, Styrene

\section{INTRODUCTION}

Polystyrene is thermoplastic which is a clear, amorphous, nonpolar commodity. It is a good electrical insulator, has excellent optical clarity due to the lack of crystallinity, and has good chemical resistance to dilute acids and bases. According to these properties, they are used in different fields such as insulation materials, pipes, auto parts and panels. But, physical, chemical and mechanical properties of them are generally nearly related with their molecular weights. Low molecular weight polymers have ineffectual molecular properties and they interact with different chemicals. The full molecular weight distribution (MWD) of a specific polymer and ratio of moments of this distribution, such as the number average $(\mathrm{Mn})$ or the weight average $(\mathrm{Mw})$ molecular weight, are effective on the mechanical properties of the polymers. Polymers with small molecules whose molecular weight does not exceed a certain value readily interact with various chemicals and have poor mechanical properties. Therefore, the molecular weight of the polymers is very important according to the field of use [1-2]. Since polymerization reactions are exothermic and complex, temperature control is very important for the desired polymer quality [3]. Several control methods have been applied to the polymerization reactors to obtain high quality polymer [4-5]. Although Deadbeat control method has been used in some studies [6, 7], the application of Deadbeat control to polymerization reactor is very limited [z.zeybek, 2003].

In the present study, Deadbeat control method was applied experimentally at the constant temperature to control a polymerization reactor.

\section{MATERIALS AND METHOD}

\subsection{Experimental}

Experimental studies were carried out in a $1.1 \mathrm{~L}$ glass jacketed cylindrical vessel as shown Figure 1. There are three thermocouples and a mixer in the reactor. The polymerization reactor, the jacket inlet and outlet temperatures were monitored on the computer during the styrene polymerization.

*Corresponding Author danakli80@gmail.com

Received: 05.10.2019 Published: 16.12.2019 
Thermocouples were used to measure inside temperature of the reactor and transferred to the computer. Commercial styrene and toluene solvent (30\%) were first added to the reactor.

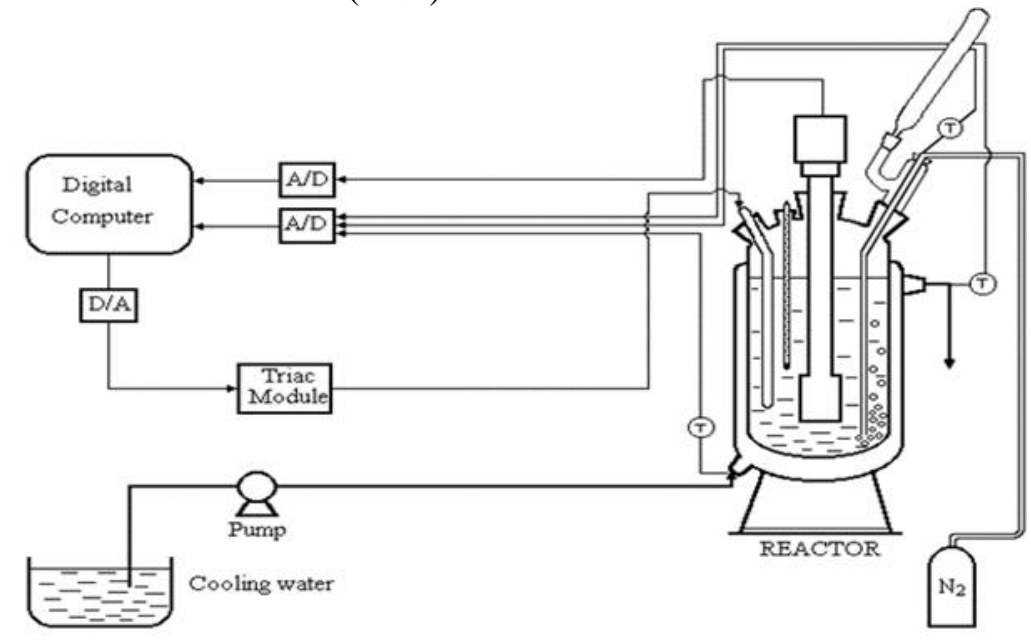

Figure 1. Experimental System

The reactor was heated to the desired temperature before started the polymerization. Polymerization reaction was started after the addition of the benzoyl peroxide solution as initiator into reactor and then Deadbeat control was used to keep the reactor temperature at the desired value. Polymer samples were withdrawn from the reactor for conversion and molecular weight analysis during the polymerization. Optimal operating conditions to achieve a predetermined conversion and number of average chain length in a minimum time were determined by applying Lagrange's multiplier method for the mathematical modeling of the reactor system [9] .

\subsection{Deadbeat Control}

The purpose of Deadbeat conroller is to obtain a desired condition by using the difference between the measured output and the set point. Deadbeat control action can be described quantitatively by [8]

$$
D(z)=\frac{1}{H G_{p}(z)} \frac{\hat{y}(z) / \hat{y}_{s p}(z)}{1-\hat{y}(z) / \hat{y}_{s p}(z)}
$$

The unit step change in the set point is

$$
\hat{y}_{s p}(z)=\frac{1}{1-z^{-1}}
$$

The response with a unit step and a unit dealy

$$
\hat{y}(z)=\frac{z^{-1}}{1-z^{-1}}
$$

Therefore,

$$
\frac{\hat{y}(z)}{\hat{y}_{s p}(z)}=z^{-1}
$$


Transfer function for a Deadbeat controller in z domain

$$
D(z)=\frac{1}{H G_{p}(z)} \frac{z^{-1}}{1-z^{-1}}
$$

and

$$
H G p(z)=\frac{b_{0} z^{-1}}{1+a_{1} z^{-1}+a_{2} z^{-2}}
$$

The discrete time version of deadbeat is given as follows:

$$
\begin{gathered}
\frac{C(z)}{\varepsilon(z)}=\frac{1+a_{1} z^{-1}+a_{2} z^{-2}}{b_{0}\left(1-z^{-1}\right)} \\
C_{n}-C_{n-1}=\left[\frac{1}{b_{0}}\right] \varepsilon_{n}+\left[\frac{a_{1}}{b_{0}}\right] \varepsilon_{n-1}+\left[\frac{a_{2}}{b_{0}}\right] \varepsilon_{n-2}
\end{gathered}
$$

The Deadbeat control algorithm has a sampling period of $\mathrm{T}=1 \mathrm{~s}$. In the algorithm, the dead time is accepted as zero. The estimated model was assumed as the discrete time version in the following form:

$$
D(z)=\frac{1+a_{1} z^{-1}+a_{2} z^{-2}}{b_{0} z^{-1}}
$$

These coefficients $\left(b_{0}, a_{1}\right.$ and $\left.a_{2}\right)$ were obtained by using a pseudo random binary sequence as input function. The system is defined and the model parameters, calculated using the least squares regression method are shown as follows.

Regression coefficient $\left(\mathrm{R}_{2}\right)$ is found 0.96 :

$a_{1}=1.1202443 \times 10^{-7}, a_{2}=-8.986674 \times 10^{-8}, b_{0}=7.02117 \times 10^{-8}$

\section{RESULT AND DISCUSSION}

Optimal operating conditions are shown in Table 1 . The calculated optimal constant temperature $\left(103.8^{\circ} \mathrm{C}\right)$ was used as set point to reach desired values (the monomer conversion, number average chain length and average viscosity molecular weight) at minimum time (Table 1 ).

Table 1. Optimal operating conditions used in experimental studies

\begin{tabular}{cccccc}
\hline $\mathrm{m}^{*}(\%)$ & $\mathrm{X}_{\mathrm{n}}{ }^{*}$ & $\mathrm{M}_{0}\left(\mathrm{~mole} \mathrm{l}^{-1}\right)$ & $\mathrm{I}_{0}\left(\mathrm{~mole} \mathrm{l}^{-1}\right)$ & $\mathrm{T}_{\mathrm{Ri}}\left({ }^{\mathrm{o}} \mathrm{C}\right)$ & $\mathrm{t}_{\mathrm{f}}(\mathrm{min})$ \\
\hline 50 & 500 & 6.092 & 0.0126 & 103.8 & 152 \\
\hline
\end{tabular}

The polymerization reactor temperature was controlled by manipulating the power to the heater and monitored to see the control perfomance. Figure 2 shows open-loop state that is when the reactor containing only the solvent is at steady state condition, benzoly peroxide is added. Then the temperature increaeses as an exothermic property of the reaction so control algorithms were used to bring the reactor temperature to the set point $\left(103.8^{\circ} \mathrm{C}\right)$. 


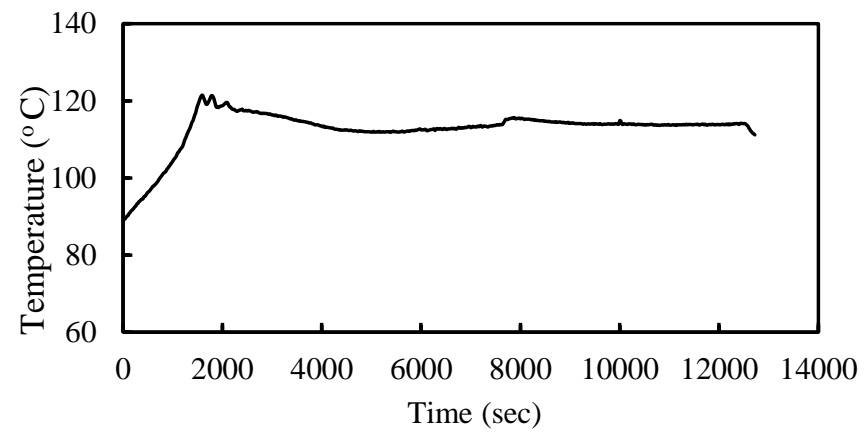

Figure 2. Open-loop

Figure 3a shows the results of experimental and theoretical temperature response of Deadbeat control for polymer system in the polymerization reactor with optimal condition $\left(\mathrm{I}_{0}=0.0126 \mathrm{~mole}^{-\mathrm{L}^{-1}, \mathrm{~T}_{\mathrm{set}}=103.8}\right.$ ${ }^{\circ} \mathrm{C}$ ). Manipulated variable change with time during the control is also seen in the figure (Figure $3 \mathrm{~b}$ ). While simulation result given in Figure 3(a) indicates that the reactor temperature follows perfectly the temperature set point, some oscillations of reactor temperature is observed on experimental study. In the experimental study, although the oscillations appear at the beginning of the experimental study, it is observed that it catches the set point after $4000 \mathrm{~s}$ and follows the set point until the end of the experiment.

(a)

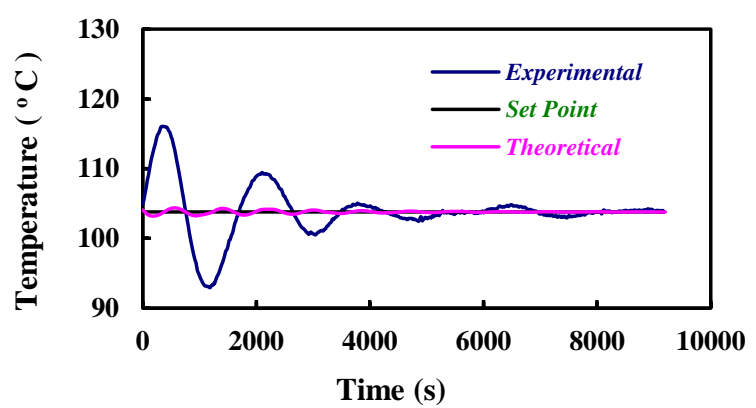

(b)

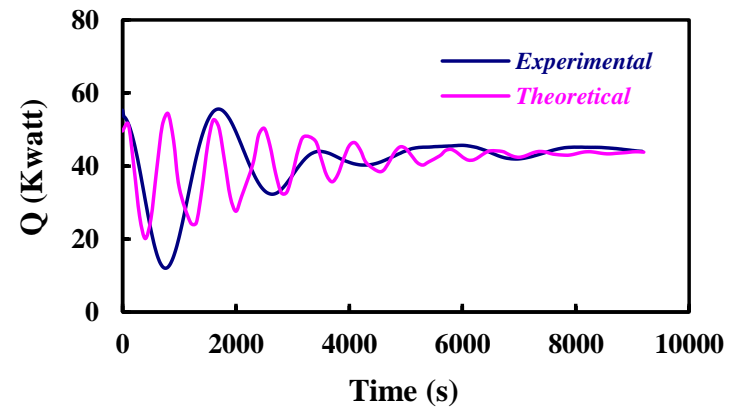

Figure 3. (a) Temperature response and (b) the change of manipulated variable (experimental and theoretical) with time under Deadbeat control

The monomer conversion, number average chain length and average viscosity molecular weight values measured have been compared with target values (Table 2). It is observed from the table that the experimental data are close to the desired values.

Table 2. Comparison of experimental results with target values

\begin{tabular}{ll}
\hline $\mathrm{T}\left({ }^{\circ} \mathrm{C}\right)$ & 103.8 \\
$\mathrm{I}_{0}\left(\mathrm{~mole} \mathrm{~L}^{-1}\right)$ & 0.0126 \\
Desired conversion, $\mathrm{m}^{*}(\%)$ & 50 \\
Experimental monomer conversion, $\mathrm{m}(\%)$ & 57.1 \\
Desired chain length, $\mathrm{X}_{\mathrm{n}}{ }^{*}$ & 500 \\
Experimental chain length, $\mathrm{X}_{\mathrm{n}}$ & 405.65 \\
Desired average viscosity molecular weight, $\mathrm{M}_{\mathrm{w}}{ }^{*}$ & 52000 \\
Experimental average viscosity molecular weight, $\mathrm{M}_{\mathrm{w}}$ & 42244.93 \\
\hline
\end{tabular}




\section{CONCLUSION}

In this study, Deadbeat control strategy was performed experimentally and theoretically to control the temperature in a batch polymerization reactor. Some oscillations were seen the experimental result. This is thought to be due to the polymerization gel effect. However, it was observed in the experimental study that it caught the set point and followed it to the end of the experiment. It is obtained that desired final conversion and number average chain length values were almost achieved. Based on the experimental results, the implementation of a Deadbeat controller for temperature control of batch polymerization reactors is encouraging.

\section{NOMENCLATURE}

$a_{i} \quad$ parameters of A polynomial

$C\left(z^{-1}\right) \quad$ monic polynomial in $\mathrm{z}$ domain representing the zeros of the process noise, calculated

control output for Deadbeat algorithm

$G_{p(z)} \quad$ process transfer function at $\mathrm{z}$ domain

$H \quad$ Hamiltonian

$Q \quad$ heat power $(\mathrm{kW})$

$I_{0} \quad$ initiator concentration $\left(\right.$ mole L $\left.^{-1}\right)$

$m^{*} \quad$ desired monomer conversion (\%)

$X_{n}, X_{n}^{*} \quad$ number of average chain length, desired number of average chain length, respectively.

$y(z) \quad$ output variable in $\mathrm{z}$ domain

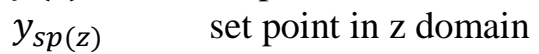

Greek letter

$\varepsilon(z) \quad$ error in $\mathrm{z}$ domain

\section{REFERENCES}

[1] Tobita H. Model-based reactor design in free-radical polymerization with simultaneous long-chain branching and scission. Process 2015; 3 (4): 731-748.

[2] Tobita H. Simultaneous Long-Chain Branchingand Random Scission: I.Monte Carlo Simulation. Journal of Polymer Science: PartB: Polymer Physics 2001; 39, 391-403.

[3] Yüce S, Hasaltun A, Erdoğan S, Alpbaz M. Temperature control of a batch polymerization reactor. Trans IchemE 1999; 77 (A), 413-419.

[4] Zeybek Z, Çetinkaya S, Hapoğlu H, Alpbaz M. Generalized Delta Rule (GDR) Algorithm with Generalized Predictive Control (GPC) for Optimum Temperature Tracking of Batch Polymerization. Chemical Engineering Science 2006; 61, 6691-6700.

[5] Çetinkaya S, Zeybek Z. Hapoğlu H. Alpbaz M. Optimal Temperature Control in a Batch Polymerization Reactor Using Fuzzy-Relational Models-Dynamics Matrix Control. Computer and Chemical Engineering 2006; 30, 1315-1323.

[6] Yunfei L, Chengning Z. A Comparative Experimental Analysis of PMSM between Deadbeat Prediction Current Control and Field-oriented Control. Energy Procedia 158 2019; 2488-2493.

[7] Hamdy M, Shalaby R, Sallam M. A hybrid partial feedback linearization and deadbeat control scheme for a nonlinear gantry crane. Journal of the Franklin Institute 355 2018; 6286-6299. 
[8] Zeybek Z, Yüce S, Hapoğlu H, Alpbaz M. Adaptive heuristic temperature control of a batch polymerization reactor. Chemical Engineering and Processing 2004; 43, 911-920.

[9] Ponnuswamy SR, Shah SI, Kiparissides CA. Computer optimal control of batch polymerization reactors. Ind. Eng. Chem. Res. 21987; 6( (11), 2929-2236. 